\title{
Enhancing the Behaviour Change Wheel with synthesis, stakeholder involvement and decision-making: a case example using the 'Enhancing the Quality of Psychological Interventions Delivered by Telephone' (EQUITy) research programme
}

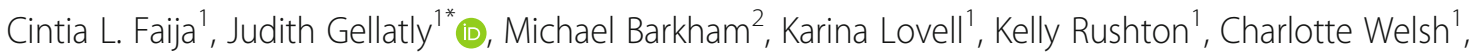
Helen Brooks ${ }^{3}$, Kerry Ardern ${ }^{4}$, Penny Bee ${ }^{1}$ and Christopher J. Armitage ${ }^{5,6,7}$

\begin{abstract}
Background: Using frameworks such as the Behaviour Change Wheel to develop behaviour change interventions can be challenging because judgement is needed at various points in the process and it is not always clear how uncertainties can be resolved. We propose a transparent and systematic three-phase process to transition from a research evidence base to a behaviour change intervention. The three phases entail evidence synthesis, stakeholder involvement and decision-making. We present the systematic development of an intervention to enhance the quality of psychological treatment delivered by telephone, as a worked example of this process.

Method: In phase 1 (evidence synthesis), we propose that the capabilities (C), opportunities $(O)$ and motivations (M) model of behaviour change (COM-B) can be used to support the synthesis of a varied corpus of empirical evidence and to identify domains to be included in a proposed behaviour change intervention. In phase 2 (stakeholder involvement), we propose that formal consensus procedures (e.g. the RAND Health/University of California-Los Angeles Appropriateness Methodology) can be used to facilitate discussions of proposed domains with stakeholder groups. In phase 3 (decision-making), we propose that behavioural scientists identify (with public/ patient input) intervention functions and behaviour change techniques using the acceptability, practicability, effectiveness/cost-effectiveness, affordability, safety/side-effects and equity (APEASE) criteria.

\footnotetext{
* Correspondence: Judith.l.gellatly@manchester.ac.uk

'Division of Nursing, Midwifery and Social Work, School of Health Sciences,

Faculty of Biology, Medicine and Health, University of Manchester,

Manchester Academic Health Science Centre, Manchester, UK

Full list of author information is available at the end of the article
}

(c) The Author(s). 2021 Open Access This article is licensed under a Creative Commons Attribution 4.0 International License, which permits use, sharing, adaptation, distribution and reproduction in any medium or format, as long as you give appropriate credit to the original author(s) and the source, provide a link to the Creative Commons licence, and indicate if changes were made. The images or other third party material in this article are included in the article's Creative Commons licence, unless indicated otherwise in a credit line to the material. If material is not included in the article's Creative Commons licence and your intended use is not permitted by statutory regulation or exceeds the permitted use, you will need to obtain permission directly from the copyright holder. To view a copy of this licence, visit http://creativecommons.org/licenses/by/4.0/ The Creative Commons Public Domain Dedication waiver (http://creativecommons.org/publicdomain/zero/1.0/) applies to the data made available in this article, unless otherwise stated in a credit line to the data. 
(Continued from previous page)

Results: The COM-B model was a useful tool that allowed a multidisciplinary research team, many of whom had no prior knowledge of behavioural science, to synthesise effectively a varied corpus of evidence (phase 1: evidence synthesis). The RAND Health/University of California-Los Angeles Appropriateness Methodology provided a transparent means of involving stakeholders (patients, practitioners and key informants in the present example), a structured way in which they could identify which of 93 domains identified in phase 1 were essential for inclusion in the intervention (phase 2: stakeholder involvement). Phase 3 (decision-making) was able to draw on existing Behaviour Change Wheel resources to revisit phases 1 and 2 and facilitate agreement among behavioural scientists on the final intervention modules. Behaviour changes were required at service, practitioner, patient and community levels.

Conclusion: Frameworks offer a foundation for intervention development but require additional elucidation at each stage of the process. The decisions adopted in this study are designed to provide an example on how to resolve challenges while designing a behaviour change intervention. We propose a three-phase process, which represents a transparent and systematic framework for developing behaviour change interventions in any setting.

Keywords: Behaviour Change Wheel, Mental health services, Improving Access to Psychological Therapies (IAPT), Psychological interventions, Guided-self-help, Telephone, Intervention development, Implementation, Remote working

\section{Contributions to the literature}

- Using systematic guidelines to develop behaviour change interventions requires judgements, which can be opaque.

- We propose a three-phase process, namely, evidence synthesis, stakeholder involvement and decision-making to move from the evidence base to the intervention involving and incorporating stakeholder perspectives into the design process.

- We believe this approach represents a transparent and systematic framework for developing behaviour change interventions in any setting.

\section{Introduction}

The Behaviour Change Wheel [1] is a systematic method that is endorsed as a key theoretical framework by the National Institute for Health and Care Excellence (NICE) [2] for the development and evaluation of behaviour change interventions. The Behaviour Change Wheel [1] makes explicit many of the processes involved in the development of behaviour change interventions, the starting point for which is understanding the behaviour (e.g. identifying what needs to change), followed by identifying intervention options and identifying content. The Behaviour Change Wheel [1] also provides tools for negotiating each of these phases of intervention development. For example, the capabilities $(\mathrm{C}$, physical and psychological), opportunities (O, physical and social) and motivations ( $M$, automatic and reflective) model of behaviour (B: COM-B) captures the key drivers of behaviour that may need to change, and APEASE articulates the criteria (acceptability, practicability, effectiveness/ cost-effectiveness, affordability, safety/side-effects and equity) by which decisions about intervention content (e.g. mode of delivery) should be made [1].

However, the operative word in relation to the Behaviour Change Wheel [1] is method, and although the Behaviour Change Wheel suggests a series of broad steps to follow in developing interventions it is not a 'magic bullet' ([1]: p.27). This means that every step in the process of intervention development is not prescribed and that developers need to 'be comfortable using judgement' ([1]: p.125) to decide what suits best for the context. There is currently a lack of worked examples of how to identify and then negotiate the likely numerous points at which judgement is needed to develop coherent and effective interventions. This is important, because there are numerous examples of the Behaviour Change Wheel [1] being used to develop interventions that lack of transparency in how key decisions were made. For example, although Barker et al. [3] rigorously apply the Behaviour Change Wheel [1], it is not clear how they synthesised their varied corpus of evidence to arrive at their final intervention ('we then combined...', p. 491). The lack of specified opportunities for stakeholder involvement, a core philosophy of contemporary health care [4], has been acknowledged as a specific weakness in the implementation of the Behaviour Change Wheel approach [5].

\section{Aims}

The aim of this paper is to propose a transparent and systematic process for intervention development: (1) evidence synthesis, how to bring together evidence from multiple sources; (2) stakeholder involvement, how to incorporate stakeholder perspectives on the evidence base; and (3) decision making, how to resolve contradictions in the evidence base and/or stakeholder 
perspectives (see Fig. 1). We describe how the transition from empirical evidence (evidence synthesis) to the development of behaviour change intervention materials (decision-making) can be negotiated, considering key stakeholder priorities (stakeholder involvement).

Our worked-example reports on each phase of the development of a behaviour change intervention designed to enhance the quality of psychological interventions delivered by telephone (EQUITy research programme). Mental health problems are affecting an increasing number of people [6] and a critical step in maximising the availability, accessibility and cost-effectiveness of evidence-based mental healthcare is to develop and implement high quality, safe alternatives to face-to-face treatment. Although meta-analysis, randomised trials and large observational studies have shown telephonedelivered psychological interventions to be clinically and cost-effective compared to face-to-face delivery [7-9], their routine uptake in practice and their sustained use by patients has lagged behind this evidence [10, 11]. Qualitative enquiry has shown the root of this delay to be a multifaceted problem, driven not just by the behaviour of patients themselves, but also by the practitioners delivering psychological services, and the people who manage them [12-15]. Enhancing the quality of psychological interventions delivered by telephone thus provides a rich and contemporary relevant context to illuminate some of the processes involved in behaviour change intervention development.

\section{Phase 1: Evidence synthesis Introduction}

Evidence is at the heart of the Behaviour Change Wheel [1] approach to intervention development, but questions inevitably arise as to what types of evidence are relevant, how much of each type of evidence is necessary and how might intervention developers best prioritise or bring different types of evidence together. We have labelled the first phase of the development of our workedexample intervention 'evidence synthesis'. Evidence synthesis may be required at each phase of intervention development specified in the Behaviour Change Wheel [1]: it can be used to identify what needs to change as well as what modes of delivery might be most effective.

Systematic reviews and meta-analysis are at the top of the evidence hierarchy $[16,17]$ and are extremely useful when they are available, but they rarely cover every aspect of the intervention that needs to be developed (e.g. from selecting target behaviours to identifying mode of delivery). Thus, when embarking on intervention development, there are often gaps in existing knowledge that need addressing rapidly. This might mean additional data collection (qualitative and/or quantitative) and/or rapid evidence reviews are required to fill gaps in systematic reviews. However, the challenge is to identify a structured way in which to synthesise such evidence from multiple sources that maximises input from people who may not have a behavioural sciences background, let alone familiarity with the Behaviour Change Wheel [1].

\section{Methods}

How to bring together evidence from multiple studies/sources? Ideally, and upholding the central ethos of evidence-based health care, synthesis would be achieved by conducting a mixed-methods meta-synthesis based on published papers. In addition, training stakeholders in research methods and the Behaviour Change Wheel so that they could fully and robustly participate in evidence synthesis would integrate and enable coproduction. Often however, intervention needs to be articulated through a lens of tacit demand or more acute system changes, evidence gaps, publication delays or

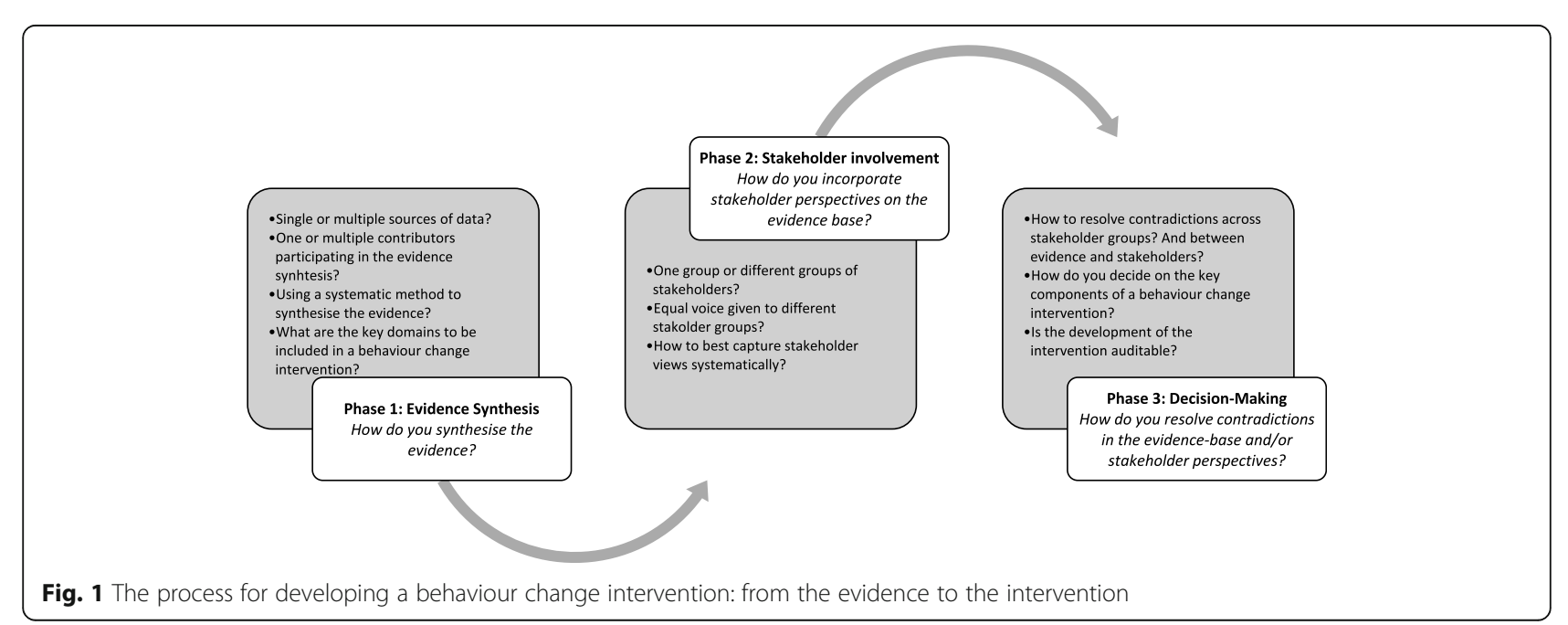


funding windows that introduce time pressures into real-world scenarios. In such situations, judgment is needed $[18,19]$.

Table 1 summarises the steps needed to negotiate the evidence synthesis phase, alongside suggestions as to how to strike a balance between the ideal of mixed-methods meta-synthesis with the realities of intervention development. Key features of the process include the idea that the personnel involved should be as broad as possible and the recommendation that COM-B be used to help structure people's responses. We have found that COM-B is easily communicated to non-experts. Additional Files 1, 2, 3 and 4 provide a worked example of the approach in relation to improving quality and engagement on telephone working and increase likelihood of effective and successful implementation of an intervention in clinical practice.

\section{Results}

What was the output from the evidence synthesis phase? The evidence synthesis phase resulted in 93 domains of people's capabilities, opportunities and motivations that needed to change to improve delivery of psychological interventions by telephone (Additional File 5). From the 93 domains, 40 were related to capabilities (all psychological), 31 to opportunities (18 physical and 13 social) and 22 to motivations (16 reflective and 6 automatic). The target domains involved changes at practitioner, patient, service and community levels.
In brief, changes at a practitioner level included mainly development/enhancement of telephone-specific skills (capabilities); changes in negative beliefs and emotions associated to telephone treatment and acknowledgement of professional role expectations (motivation). Changes at patient and community levels were related to increased knowledge/awareness of the different types of psychological interventions and its different modes of delivery (capabilities). Changes at a service level consisted of providing standardised and clear guidelines on procedures to deliver psychological treatment by telephone and clarify drivers for its use (capabilities); adjust working environment (e.g. reduce noise) (opportunities), ensure resources (e.g. good quality headsets) (opportunities), provide social support for working remotely (e.g. assessment and monitoring of telephone performance) (opportunities) and continued professional development (opportunities). The COM-B domains correspond closely with those that are articulated in the Theoretical Domains Framework (TDF) [20], and evidence analysed using different theoretically informed approaches was synthesised effectively and the relevant behaviour change domains identified.

Results of the evidence synthesis meeting were then cross-validated with broader literature relevant to the target group, identified prior to progressing to phase 2 . As part of the cross-validation, we generated a list of potential barriers/enablers to behaviour change identified via a scoping search of previously published literature conducted by members of the programme team (PB and KL) (see tables in Additional Files 1 and 2) and feedback

Table 1 Evidence synthesis phase

\begin{tabular}{|c|c|c|c|}
\hline & Ideal & Possible compromises & Worked example \\
\hline $\begin{array}{l}\text { Evidence } \\
\text { collection }\end{array}$ & $\begin{array}{l}\text { Mixed-methods meta-synthesis } \\
\text { based on published papers }\end{array}$ & $\begin{array}{l}\text { - Rapid primary data collection } \\
\text { - Rapid reviews }\end{array}$ & $\begin{array}{l}\text { - } 5 \text { primary qualitative studies } \\
\text { - } 1 \text { rapid review } \\
\text { - } 1 \text { literature mapping exercise }\end{array}$ \\
\hline Personnel & $\begin{array}{l}\text { Widest possible grouping of fully } \\
\text { trained stakeholders design and } \\
\text { conduct the mixed-methods meta- } \\
\text { synthesis }\end{array}$ & $\begin{array}{l}\text { - Multidisciplinary research team } \\
\text { - Behavioural scientists plus } \\
\text { practitioners }\end{array}$ & $\begin{array}{l}\text { - Face-to-face meeting of multidisciplinary re- } \\
\text { search team }(N=16) \text { including behavioural sci- } \\
\text { entists, academics, psychologists, mental } \\
\text { health practitioners and the patient and public } \\
\text { involvement lead }\end{array}$ \\
\hline Input & $\begin{array}{l}\text { Recommendations based on mixed- } \\
\text { methods meta-synthesis }\end{array}$ & $\begin{array}{l}\text { Accessible summaries of the key } \\
\text { findings and recommendations for } \\
\text { intervention development from } \\
\text { individual studies }\end{array}$ & $\begin{array}{l}\text { Two weeks prior to face-to-face meeting, the full } \\
\text { programme team }(N=27) \text { received: } \\
\text { - Two slides for a } 5 \text {-min presentation } \\
\text { - Single-page summaries of the key findings and } \\
\text { recommendations for each of the } 7 \text { studies and } \\
\text { comments invited. }\end{array}$ \\
\hline $\begin{array}{l}\text { Identify key } \\
\text { domains to be } \\
\text { included in } \\
\text { intervention }\end{array}$ & $\begin{array}{l}\text { Already present in mixed-method } \\
\text { synthesis conclusions }\end{array}$ & $\begin{array}{l}\text { Use COM-B to structure people's identi- } \\
\text { fication of key domains, which can be } \\
\text { completed by: } \\
\text { - Individuals } \\
\text { - Small group } \\
\text { - Facilitated large group discussions }\end{array}$ & $\begin{array}{l}\text { Face-to-face meeting attendees used post-it } \\
\text { notes to categorise intervention domains into } \\
\text { the six COM-B areas: } \\
\text { - Individually } \\
\text { - In small groups mixed by experience/expertise } \\
\text { - In facilitated large group discussion }\end{array}$ \\
\hline Cross-validation & $\begin{array}{l}\text { Experts cross-check evidence synthe- } \\
\text { sis phase with knowledge and } \\
\text { experience }\end{array}$ & $\begin{array}{l}\text { Experts cross-check evidence synthesis } \\
\text { phase with knowledge and experience }\end{array}$ & $\begin{array}{l}\text { Identification of potential barriers/enablers to } \\
\text { behaviour change identified via a scoping search } \\
\text { of previously published literature conducted by } \\
\text { PB and KL }\end{array}$ \\
\hline
\end{tabular}


gathered from clinical work. We included studies focused on the same target populations (patient, practitioners) and health intervention (telephone-delivered psychological interventions), irrespective of whether or not they used a TDF analysis. We then compared our generated list of extrapolated influences to the specific evidence we had generated to inform the design of the intervention. Team consensus considered all potential influences to be adequately represented by our evidence synthesis output, and no further additions to our data set were required.

\section{Phase 2: Stakeholder involvement Introduction}

Patient and public involvement (PPI) plays an active role in health and social care services and in research, and its importance is rising [4, 21]. The Behaviour Change Wheel approach [1] has been criticised for its lack of patient involvement [5]. Involvement of the public is needed to ensure development and improvement in service care is equal, efficient, effective, patient-centred, relevant and appropriate [22-24]. Further to the crossvalidation exercise proposed at the end of phase 1, an additional sense-checking of these results with multiple stakeholder groups is necessary. The challenge is to ensure that different perspectives have equal contributions while developing a coherent intervention.

\section{Methods}

There are multiple ways in which stakeholders can be involved in the translation of evidence into practice, such as the Delphi method [25], the Nominal Group Technique $[26,27]$, and the Consensus Development Conference [28, 29], but most force participants to achieve consensus [30]. Forced consensus may inhibit creativity and lose important nuance in intervention design. We would therefore propose an adapted version of the RAND Health/University of California-Los Angeles Appropriateness Methodology (RAND/UCLA) [31], which does not force consensus and provides participants with opportunities to discuss and change ratings after further considerations. The RAND/UCLA method usually involves single groups of experts, but we would advocate adapting the methodology by: (a) considering all potential participants as experts, and (b) running RAND/UCLA exercises separately for different groups of stakeholders in order to capture the expertise of all stakeholders without inhibition (e.g. practitioners versus managers). Additional File 6 provides details on recruitment of stakeholders and describes RAND/ UCLA procedures and adaptations.

Table 2 summarises the steps needed to negotiate the stakeholder involvement phase, alongside suggestions as to how to adapt the RAND/UCLA method to meet this purpose. Key features of the process include the idea that the personnel involved should not be restricted to 'experts', but that different stakeholder groups be treated separately. Additional File 6 provides a worked example of the approach in relation to improving quality and engagement on telephone working and increase likelihood of effective and successful implementation of an intervention in clinical practice. Additional File 7 includes demographic characteristics for the stakeholder groups. Experiences of stakeholders related to taking part in the meeting are included in Additional File 8. A questionnaire aimed to gather information at the stakeholder meetings on a proposed element of the behaviour change intervention (i.e. skills training) is included in Additional File 9.

\section{Results}

What was the outcome of the stakeholder involvement phase? At the end of Round 1, 'extremely important' ratings (i.e. Median $\geq 7$ ) had been given to $90.3 \%$ of domains by patients, $84.9 \%$ by practitioners and 90.3\% by key informants. Following moderated discussion during Round 2, an additional 3.2\% and 7.5\% domains were rated 'extremely important' by patients and practitioners respectively; no additional domains were

Table 2 Stakeholder involvement phase

\begin{tabular}{|c|c|c|c|}
\hline & Standard RAND/UCLA & Adapted RAND/UCLA & Worked example \\
\hline Inputs & $\begin{array}{l}\text { Series of systematic reviews/meta- } \\
\text { analyses }\end{array}$ & Intervention domains from phase 1 & 93 domains identified in phase 1 \\
\hline Stakeholders & Experts & $\begin{array}{l}\text { As broad as possible, being mindful of } \\
\text { traditionally excluded groups }\end{array}$ & $\begin{array}{l}\text { - Patients }(n=9) \\
\text { - Practitioners }(n=19) \\
\text { - Key informants }(n=15)\end{array}$ \\
\hline $\begin{array}{l}\text { Number of } \\
\text { rounds }\end{array}$ & $\begin{array}{l}\text { 3: } \\
\text { - Individual ratings of } \\
\text { appropriateness } \\
\text { - Moderated group ratings of } \\
\text { appropriateness } \\
\text { - Individual ratings of necessity }\end{array}$ & $\begin{array}{l}3 \text { per group of stakeholders: } \\
\text { - Individual ratings of importance } \\
\text { - Moderated group ratings of items rated } \\
\text { 'not important' } \\
\text { - Individual ratings of 'how essential?' }\end{array}$ & $\begin{array}{l}\text { Separate meetings of patients, practitioners and } \\
\text { key informants completing: } \\
\text { - Individual ratings of importance } \\
\text { - Moderated group ratings of items rated 'not } \\
\text { important' } \\
\text { - Individual ratings of 'how essential?' }\end{array}$ \\
\hline $\begin{array}{l}\text { Critical cut- } \\
\text { offs }\end{array}$ & $\begin{array}{l}\text { Median of }=>7 \text { on } 1-9 \text { point } \\
\text { Likert-type scales }\end{array}$ & $\begin{array}{l}\text { Median of }=>7 \text { on 1-9 point Likert-type } \\
\text { scales }\end{array}$ & Median of $=>7$ on 1-9 point Likert-type scales \\
\hline
\end{tabular}


rated as extremely important by key informants. Details including ratings for Round 1 and Round 2 for each stakeholder group are included in Additional File 10, and minutes from moderated discussions are included in Additional File 11. Data from Round 3 showed that $89.2 \%$ of domains by patients, $89.2 \%$ by practitioners and $62.4 \%$ by key informants were rated as 'essential' (i.e. Median $\geq 7$ ) and were taken forward to phase 3 (see Additional File 12a). Domains rated at Round 3 as 'not essential' (i.e. median $<7$ ) are included in Additional File 12b. Experiences from each of the stakeholder groups about their participation in the meeting are included in Additional File 13.

\section{Phase 3: Decision-making}

\section{Introduction}

The principal aims of the decision-making phase are to (a) address how to resolve any contradictions in the evidence base and/or across stakeholder perspectives, (b) choose which domains to include in the behaviour change intervention, (c) identify intervention functions, (d) propose behaviour change techniques [1] and (e) address demand while retaining applicability and practicality across diverse health settings/services. Consistent with the ethos of stakeholder involvement, ideally the decision-making phase would involve equitable contributions from all partners. However, the reality is that few intervention development programmes have the opportunity to train adequately all the stakeholders.

\section{Methods}

In the broader literature [32], typically final decisions on intervention content are made either by the behavioural scientist on the team or among a small number of members of the programme team. Sometimes the results are circulated and the decisions made for feedback to the wider team. With the luxury of time, key stakeholders could be trained and a larger-scale decision-making meeting could be held. Table 3 provides details on decisionmaking procedures, divided into what would ideally be done, possible compromises that could be made alongside some concrete instances from our worked example. Additional File 14 provides a more detailed worked example of the procedures taken in relation to improving quality and engagement on telephone working and increase likelihood of effective and successful implementation of an intervention in clinical practice.

\section{Results}

What was the outcome of the decision-making phase? Fifty-five domains were rated as 'essential' across all the stakeholder groups and 25 across two of them (see Additional File 12a). Thus, 80 domains from the 93 initially proposed were included in the behaviour change intervention. Domains rated as 'not essential' (i.e. median $<7$ ) by two or more stakeholder groups were not included in the intervention and are presented in Additional File 12b.

From the 80 domains agreed across the majority of stakeholder groups, 39 corresponded to capabilities (all psychological), 22 to opportunities (11 physical and 11 social) and 19 to motivation (16 reflective and 3 automatic). Changes in the behaviour of practitioners, patients, service leads and community members (e.g. general practitioners) were required. Using the APEASE

Table 3 Decision-making phase

\begin{tabular}{|c|c|c|c|}
\hline & Ideal & Possible compromises & Worked example \\
\hline Personnel & $\begin{array}{l}\text { Widest possible grouping of fully trained } \\
\text { stakeholders }\end{array}$ & $\begin{array}{l}\text { - Multidisciplinary research team } \\
\text { - Behavioural scientists plus practitioners }\end{array}$ & $\begin{array}{l}\text { Face-to-face meeting of an intervention } \\
\text { development subgroup comprised of a } \\
\text { behavioural scientist, principal investigators, } \\
\text { programme manager, researcher, patient } \\
\text { and public involvement lead }\end{array}$ \\
\hline Input & $\begin{array}{l}\text { Recommendations based on RAND/UCLA } \\
\text { analyses of multiple stakeholder groups } \\
\text { conducted separately }\end{array}$ & $\begin{array}{l}\text { Recommendations based on RAND/UCLA } \\
\text { analyses of single expert group }\end{array}$ & $\begin{array}{l}\text { Three days prior to face-to-face meeting, } \\
\text { intervention development subgroup }(n= \\
\text { 6) received output of phase } 2\end{array}$ \\
\hline $\begin{array}{l}\text { Identify } \\
\text { intervention } \\
\text { content }\end{array}$ & $\begin{array}{l}\text { All stakeholder groups agree fully on } \\
\text { intervention domains. Translate intervention } \\
\text { domains into behaviour change techniques } \\
\text { and modes of delivery using APEASE criteria }\end{array}$ & $\begin{array}{l}\text { Decide on decision rules to aid choice of } \\
\text { intervention domains. Translate } \\
\text { intervention domains into behaviour } \\
\text { change techniques and modes of delivery } \\
\text { using APEASE criteria }\end{array}$ & $\begin{array}{l}\text { Agree criterion of two or more stakeholder } \\
\text { groups from phase two rating domains as } \\
\text { 'essential' (i.e. Median } \geq 7 \text { on round } 3 \text { ). } \\
\text { Translate intervention domains into } \\
\text { behaviour change techniques and modes } \\
\text { of delivery using APEASE criteria }\end{array}$ \\
\hline $\begin{array}{l}\text { Final } \\
\text { approvals }\end{array}$ & $\begin{array}{l}\text { Full multidisciplinary research team and all } \\
\text { stakeholders provided with intervention } \\
\text { materials for feedback. } \\
\text { Details of the behaviour change } \\
\text { intervention described using the Template } \\
\text { for Intervention Description and Replication } \\
\text { (TIDieR) }\end{array}$ & $\begin{array}{l}\text { Subgroup of multidisciplinary research } \\
\text { team and stakeholders provided with } \\
\text { intervention materials for feedback. } \\
\text { Details of the behaviour change } \\
\text { intervention described using the Template } \\
\text { for Intervention Description and } \\
\text { Replication (TIDieR) }\end{array}$ & $\begin{array}{l}\text { Full multidisciplinary research team } \\
\text { provided with intervention materials for } \\
\text { feedback. } \\
\text { Details of the behaviour change } \\
\text { intervention described using the Template } \\
\text { for Intervention Description and Replication } \\
\text { (TIDieR) }\end{array}$ \\
\hline
\end{tabular}


criteria, it was decided that changes in practitioner behaviour would be addressed in training and that changes in other targets would be made through leaflets, posters and booklets. Changes in behaviours across the different target levels are equally important and interact between each other (see Additional File 15). We use the APEASE to retain applicability and practicality across diverse health settings/services.

The 80 domains agreed for inclusion in the behaviour change intervention, along with intervention functions and behaviour change techniques are presented in Additional File 16. COM-B domains included in the behaviour change intervention for each of the target levels (i.e. services, practitioners and patients) are presented in Table 4. The TIDieR Checklist [33] including the description of the behaviour change intervention is presented in Additional File 17.

\section{Discussion}

Behaviour change is more likely to be achieved if decisions as to intervention content are made following systematic guidelines such as those proposed in the Behaviour Change Wheel approach [1]. However, frameworks and guidelines offer a foundation for intervention development but require additional elucidation at each stage of the process, and our study provides a worked example of how to navigate through those challenges balancing theory, practicalities, resources and time.

The present research thus illuminates the sometimesopaque transition from a research evidence base to a behaviour change intervention aiming to improve quality and engagement of telephone treatment in mental health services. We articulated three phases, namely, evidence synthesis, stakeholder involvement and decision-making in the development of our intervention. This research makes important contributions to the literature by providing solutions for addressing uncertainties about where and how judgement might be needed while developing an evidence-based behaviour change intervention. It additionally provides clear direction on how to optimise implementation of a behaviour change intervention to improve psychological interventions delivered by telephone in a complex system, aligning with Moore et al.'s [34] view of interventions as events within complex social systems, mental health policy and service improvement. The following discussion focuses on exploring the challenges we faced at each of our three proposed phases (i.e. evidence synthesis, stakeholder involvement and

Table 4 COM-B domains included in the behaviour change intervention targeted at services, practitioner and patient level

\begin{tabular}{|c|c|c|c|c|}
\hline & & \multicolumn{3}{|l|}{ Target levels } \\
\hline \multicolumn{2}{|c|}{ COM-B DOMAINS } & Services & Practitioners & Patients \\
\hline \multirow[t]{2}{*}{ CAPABILITY } & $\begin{array}{l}\text { Physical } \\
\text { capability }\end{array}$ & & & \\
\hline & $\begin{array}{l}\text { Psychological } \\
\text { capability }\end{array}$ & $\begin{array}{l}\text { - Provide knowledge on } \\
\text { procedures and guidelines to } \\
\text { deliver psychological } \\
\text { interventions remotely } \\
\text { - Boost practitioners' telephone } \\
\text { skills }\end{array}$ & $\begin{array}{l}\text { - Provide knowledge about the } \\
\text { origins, drivers, and processes of } \\
\text { telephone treatment } \\
\text { - Develop telephone skills to enable a } \\
\text { good therapeutic relationship, } \\
\text { improve patient engagement, } \\
\text { deliver patient-centred care, and ef- } \\
\text { fectively deliver treatment without } \\
\text { visual aids and non-verbal cues }\end{array}$ & $\begin{array}{l}\text { - Improve knowledge on } \\
\text { psychological treatments (e.g. } \\
\text { counselling, cognitive behavioural } \\
\text { therapy, guided-self-help) and its } \\
\text { different modes of delivery (e.g. } \\
\text { face-to-face, telephone, group, } \\
\text { online) }\end{array}$ \\
\hline \multirow[t]{2}{*}{ OPPORTUNITY } & $\begin{array}{l}\text { Physical } \\
\text { opportunity }\end{array}$ & $\begin{array}{l}\text { - Ensure practitioners are working } \\
\text { in a comfortable and confidential } \\
\text { environment } \\
\text { - Ensure resources needed for } \\
\text { telephone delivery are available }\end{array}$ & & \\
\hline & $\begin{array}{l}\text { Social } \\
\text { opportunity }\end{array}$ & $\begin{array}{l}\text { - Provide regular assessment and } \\
\text { monitoring of telephone } \\
\text { performance in service } \\
\text { - Promote learning and } \\
\text { collaborative work across } \\
\text { practitioners }\end{array}$ & $\begin{array}{l}\text { - Provide assessment and monitoring } \\
\text { of telephone performance during } \\
\text { training and clinical practice }\end{array}$ & \\
\hline \multirow[t]{2}{*}{ MOTIVATION } & $\begin{array}{l}\text { Automatic } \\
\text { motivation }\end{array}$ & & $\begin{array}{l}\text { Identify feelings related to working by } \\
\text { telephone, and discuss feelings of } \\
\text { being undervalued }\end{array}$ & \\
\hline & $\begin{array}{l}\text { Reflective } \\
\text { motivation }\end{array}$ & $\begin{array}{l}\text { - Promote reflective practice (e.g. } \\
\text { telephone performance, beliefs } \\
\text { and emotions related to working } \\
\text { remotely, professional role } \\
\text { expectations/challenges) }\end{array}$ & $\begin{array}{l}\text { - Challenge negative beliefs } \\
\text { associated to telephone treatment } \\
\text { (e.g. telephone is a lower version of } \\
\text { treatment) }\end{array}$ & \\
\hline
\end{tabular}


decision-making), and how we addressed them; in addition, the clinical implications of the intervention we developed are highlighted.

\section{Phase 1: Evidence synthesis}

Questions may arise when deciding on the best approach to integrating and synthesising data from multiple sources that have used different methods of theoryinformed analysis, such as if the use of a framework might be useful or if it would be beneficial to involve people from different disciplinary/professional perspectives closely related (or not) to the evidence.

The gaps between theory and practice interfere with the implementation of an evidence-based practice approach, and this has led to the development of different theoretical frameworks/models by which implementation might be more likely to succeed. However, choosing the most appropriate framework/model to design an intervention is challenging. We have chosen to use the Behaviour Change Wheel [1] approach, in which the COM-B and the TDF [20] models are at the core of it, because compared to other viable frameworks $[32,35]$, this offers additional advantages. Specifically, the COM-B and the TDF frameworks are closely related and offer additional, targeted and easily translatable knowledge on the determinants of behaviour change processes for other phases of the design and development of an evidence-based intervention.

The corpus of the evidence in which our intervention is grounded included multiple sources of data, highlighting that no individual source will be complete or perfect and the integration of different sources of data provides a deeper and integrated understanding of the phenomenon under investigation. It is important to highlight that a meta-analysis offers robust quality assessment on a topic (i.e. effectiveness). However, the design of an evidencebased intervention needs to be further informed by a comprehensive understanding on barriers and enablers that in our worked example are related to improve the quality of psychological treatment delivered by telephone and aid its implementation in clinical practice. Consequently, conducting several studies towards this end was key and we benefited from synthesising relevant evidence that would not have been available in a meta-analysis. We gained a deep understanding informed by the COM-B and TDF of challenges faced on the use of telephone delivery, and identified key behaviours that need to change at service, practitioner, patient and community levels to implement effectively remotely administered care in clinical practice. The involvement of a multidisciplinary programme team at early stages of the design of an intervention was crucial to bring together the expertise and skills of different professionals. In addition, from a pragmatic point of view, the evidence synthesis was performed in a single day.

\section{Phase 2: Stakeholder involvement}

One of the weaknesses in the implementation of the Behavioural Change Wheel [1] is the lack of involvement of stakeholders [5], although the situation is changing and authors are increasingly incorporating stakeholder perspectives in their intervention development [36-38]. In our worked example, we incorporated stakeholder perspectives and provided solutions to potential issues such as how to include diversity and equity of voice and power across stakeholder groups and how to capture their views in a systematic and auditable way.

The involvement of stakeholders in health and social care is highly encouraged [4]. The contributions from stakeholders in the development of a behaviour change intervention, such as the one described in our worked example, are key to ensure that views from those who will use the intervention in the real world have been included to maximise the likelihood of success at implementation. For our intervention, key stakeholder groups included patients, practitioners and key informants (e.g. service managers, clinical leads) and we gathered their opinions on the design of the behaviour change intervention using the RAND/UCLA method [31]. This method, differently to other consensus methods, provides opportunities to identify and discuss areas of agreement within and across groups of participants instead of forcing consensus. In addition, holding meetings with each group of stakeholders independently and considering the ratings provided by group separately, ensured equal opportunity and influence to inform on the intervention development process, i.e. behaviour change intervention domains endorsed as essential by each of the groups were moved into the next phase of the process. The use of a systematic method such as the RAND/UCLA provides transparency into the development of an intervention and makes the process easy to audit.

\section{Phase 3: Decision-making}

There is a gap in guidelines on the involvement of stakeholders [5] in the implementation of the behavioural change wheel [1]. The inclusion of stakeholders on the design of an intervention has its own challenges, such as how to resolve contradictions across stakeholder's perspectives and contradictions between their views and the evidence. In addition, other issues related to the last phase of the development of the intervention were related to the identification of the behaviour change domains to be included in the final intervention; once identified, how to maximise the likelihood of success and effectiveness of the intervention into clinical practice and how to ensure evaluation and replicability of the designed intervention need to be determined. 
In our worked example, domains endorsed as essential by a majority of stakeholder groups were included in the behaviour change intervention; no stakeholder group views were prioritised over others. The close interaction between a multidisciplinary programme team and groups of stakeholders such as in our example offers a feedback loop at multiple stages of the design of the intervention, maximising the potential of success and effectiveness of the intervention when implemented in clinical practice. In addition, a systematic and auditable intervention such as the one we described facilitates data to be cross-matched and the time from evaluation to refinement is likely to be more efficient and focused. Furthermore, the description of the process to develop an intervention is very much important to facilitate process evaluation [39]. Process evaluation is important to know not only if the intervention works but also to understand how it works to produce outcomes (i.e. identifying which aspects of the intervention are important, how different elements of an intervention work together, and how and intervention can be implemented in a specific context) [39]. Process evaluation would ultimately provide evidence to evaluate for intended/unintended consequences and actual effect of decisions taken in the development phase. Evidence on intervention development such as the one provided in our worked example would contribute to know how frameworks such as the Behaviour Change Wheel are being used and ultimately provide information to expand understanding on best ways to translate research into practice.

In our worked example, the developed intervention included multiple components to prompt behaviour change at service, practitioner and patient levels to improve quality of telephone-based service delivery models. In brief, the intervention focuses on:

(1) At a service level: develop robust guidelines and standardise procedures for telephone delivery, adjust professional working environment and increase resources, provide clinical support for remote delivery and opportunities for professional development.

(2) At a practitioner level: improve knowledge on the origins, drivers and processes for telephone delivery, develop practitioners telephone skills and dilute negative preconceptions about telephone treatment.

(3) At a patient level: increase awareness on different psychological treatments (e.g. counselling, cognitive behavioural therapy, guided-self-help) and the different modes of delivery (e.g. telephone, group), and challenge beliefs of remote delivery being an inferior quality of care option compared to face-to-face.

\section{Strengths and limitations}

Our work provides a transparent and systematic basis for future research aimed at developing behaviour change interventions. The development of an intervention using a systematic approach such as the behaviour change wheel offers guidelines for an effective evaluation. In addition, the use of a systematic method such as the RAND/UCLA to involve views from stakeholder groups allows equal opportunity/power, for their voices to be included on the design of the intervention. A limitation of our research is the absence of training for stakeholders in research methods and the behaviour change wheel to enable their participation at each of the development phases of the intervention; a preferable scenario if resources and time are available.

\section{Next steps}

Following the Medical Research Council guidance [40], the behaviour change intervention described in this study will be piloted in a feasibility study and then based on the results, a decision will be made regarding conducting a randomised controlled trial (RCT). The RCT aims to evaluate the effectiveness of the behaviour change intervention developed to improve quality of delivery and engagement of patients on telephone treatment for common mental health difficulties in mental health services (for more details https://fundingawards.nihr.ac.uk/award/RPPG-1016-20010; https://sites.manchester.ac.uk/equity/). A complete version of the TIDIeR checklist [33] will be made available following implementation of the intervention at the feasibility/RCT.

\section{Conclusion}

This study provides a worked example on how to overcome challenges and make judgements while using a framework approach such as the Behaviour Change Wheel. We described three phases, moving from the evidence to the intervention involving stakeholders in the design process. We believe this represents a transparent and systematic framework for developing behaviour change interventions in any setting.

\section{Abbreviations}

APEASE: Acceptability, Practicability, Effectiveness/cost-effectiveness, Affordability, Safety/side-effects and Equity; COM-B: Capabilities, Oprtunities, and Motivations model of Behaviour; EQUITy: Enhancing the quality of psychological interventions delivered by Telephone; NIHR: National Institute for Health Research; RCT: Randomised Controlled Trial; TIDieR: Template for Intervention Description and Replication; IAPT: Increasing access to psychological therapies; LEAP : Lived Experience Advisory Panel; NICE: National Institute for Health and Care Excellence; NPT: Normalization Process Theory; RAND/UCLA: RAND Health/University of California-Los Angeles Appropriateness Methodology; TDF: Theoretical Domains Framework; TFA: Theoretical Framework of Acceptability; UK: United Kingdom; WHO: World Health Organization; IAPT: Increasing access to psychological therapies; LEAP : Lived Experience Advisory Panel; NICE: National Institute for Health and Care Excellence; NPT: Normalization Process Theory; RAND/UCLA: RAND Health/University of California-Los Angeles Appropriateness Methodology; TDF: Theoretical Domains Framework; TFA: Theoretical Framework of Acceptability; UK: United Kingdom; WHO: World Health Organization 


\section{Supplementary Information}

The online version contains supplementary material available at https://doi. org/10.1186/s13012-021-01122-2.

Additional file 1. Evidence synthesis: Corpus of evidence on our worked-example

Additional file 2. Evidence synthesis: Description of attendees and procedures

Additional file 3. Matrix used for evidence synthesis of findings using the COM-B model

Additional file 4. Examples of the tasks conducted at the synthesis phase

Additional file 5. COM-B domain items and its corresponding TDF domains included in the proposed behavioural change intervention to be rated by stakeholder groups

Additional file 6. Stakeholder involvement: Recruitment and RAND/ UCLA method

Additional file 7. Demographic characteristics for the stakeholder groups

Additional file 8. Post-Meeting Experiences Questionnaire for each of the three stakeholder groups

Additional file 9. Questionnaire to gather information from practitioners and key informants views at stakeholder meetings about the portion of the intervention to be targeted with practitioners (i.e. telephone training)

Additional file 10. Domains ratings from Round 1 and Round 2 per stakeholder group

Additional file 11. Minutes from moderated discussions from domains rated as "Not important" (i.e. Median <7) at Round 1

Additional file $\mathbf{1 2}$ a Domains rated at Round 3 as "Essential" (i.e. median between 7 and 9) by patients, practitioners or key informants. b Domains rated at Round 3 as "Not essential" (i.e. median <7) by patients, practitioners or key informants

Additional file 13. Post-Meeting Experiences for each of the three stakeholder groups

Additional file 14. Decision-Making: Description of attendees and procedures

Additional file 15. Recommendations: Target levels for the behaviour change intervention

Additional file 16. Intervention function and behaviour change techniques identified using the Behaviour Change Taxonomy (Version 1) for each domain included in the behaviour change intervention

Additional file 17. The Template for Intervention Description and Replication (TIDieR) Checklist

\section{Acknowledgements}

The authors would like to thank the patients, practitioners and key informants that participated in the stakeholder meetings, and the LEAP for their contributions with reviewing documents to be used with stakeholders.

\section{Authors' contributions}

CF analysed the data. CF and CJA led the writing up of the manuscript. PB was closely involved in the drafting of the manuscript, provided intellectual and editorial input. JG, MB, KL, KR, CW, HB and KA provided intellectual and editorial input. All authors have read and approved the final manuscript.

\section{Funding}

This study is funded by the National Institute for Health Research (NIHR) Programme Grants for Applied Research (project reference: RP-PG-101620010). Armitage is supported by NIHR Manchester Biomedical Research Centre and NIHR Greater Manchester Patient Safety Translational Research Centre. The views expressed are those of the author(s) and not necessarily those of the NIHR or the Department of Health and Social Care. The funders had no role in study design, data collection, analysis or interpretation, decision to publish or preparation of the manuscript.

\section{Availability of data and materials}

The datasets supporting the conclusions of this article are included within the article (and its additional files).

\section{Declarations}

\section{Ethics approval and consent to participate}

Ethical approval was granted by the North West - Greater Manchester West Research Ethics Committee (Reference Number: 18/NW/0372; IRAS ID: 242318). All stakeholder participants provided written informed consent.

\section{Consent for publication}

Not applicable.

\section{Competing interests}

The authors declare that they have no competing interests.

\section{Author details}

${ }^{1}$ Division of Nursing, Midwifery and Social Work, School of Health Sciences, Faculty of Biology, Medicine and Health, University of Manchester, Manchester Academic Health Science Centre, Manchester, UK. ${ }^{2}$ Clinical Psychology Unit, Department of Psychology, University of Sheffield, Sheffield, UK. ${ }^{3}$ Department of Health Services Research, Institute of Population Health Sciences, University of Liverpool, Liverpool, UK. ${ }^{4}$ Department of Psychology, University of Sheffield, Sheffield, UK. ${ }^{5}$ Manchester Centre for Health Psychology, Division of Psychology and Mental Health, School of Health Sciences, Faculty of Biology, Medicine and Health, University of Manchester, Manchester, UK. ${ }^{6}$ Manchester University NHS Foundation Trust, Manchester Academic Health Science Centre, Manchester, UK. ${ }^{7} \mathrm{NIHR}$ Greater Manchester Patient Safety Translational Research Centre, Manchester, UK.

Received: 13 July 2020 Accepted: 29 April 2021

Published online: 14 May 2021

\section{References}

1. Michie S, Atkins L, West R. The Behaviour Change Wheel: a guide to designing interventions. Great Britain: Silverback Publishing; 2014.

2. National Institute for Health and Clinical Excellence (NICE). Public Health Guideline. Behaviour change: General Approaches. 2007. Available from: https://www.nice.org.uk/guidance/ph6/resources/behaviour-change-genera l-approaches-pdf-55457515717. Accessed 7 May 2020.

3. Barker F, de Lusignan S, Cooke D. Improving collaborative behaviour planning in adult auditory rehabilitation: development of the I-PLAN intervention using the Behaviour Change Wheel. Ann Behav Med. 2018; 52(6):489-500. https://doi.org/10.1007/s12160-016-9843-3.

4. INVOLVE. Briefing Notes for Researchers: involving the Public in NHS, Public Health and Social Care. Research. Eastleigh: INVOLVE; 2012.

5. O'Cathain A, Croot L, Sworn K, Duncan E, Rousseau, Turner K, et al. Taxonomy of approaches to developing interventions to improve health: a systematic methods overview. Pilot Feasibility Stud. 2019;5:41.

6. World Health Organization [WHO]. 2019. Available from: http://www.euro. who.int/_data/assets/pdf_file/0004/404851/MNH_FactSheet_ENG.pdf?ua=1. Accessed 7 May 2020

7. Hudson JL, Bower P, Kontopantelis E, Bee P, Archer J, Clarke R, et al. Impact of telephone delivered case-management on the effectiveness of collaborative care for depression and anti-depressant use: a systematic review and meta-regression. PLoS One. 2019;14(6):e0217948. https://doi. org/10.1371/journal.pone.0217948.

8. Coughtrey AE, Pistrang N. The effectiveness of telephone-delivered psychological therapies for depression and anxiety: a systematic review. J Telemed Telecare. 2016;24(2):65-74. https://doi.org/10.1177/1357633X1 6686547.

9. Castro A, Gili M, Ricci-Cabello I, Roca M, Gilbody S, Perez-Ara MA, et al. Effectiveness and adherence of telephone-administered psychotherapy for depression: a systematic review and meta-analysis. J Affect Disord. 2020;260: 514-26. https://doi.org/10.1016/j.jad.2019.09.023.

10. National Institute for Health Research. Patient and public involvement in health and social care research: a handbook for researchers. London: National Institute for Health Research; 2014.

11. Parry GD, Barkham M, Brazier J, Dent-Brown K, Hardy G, Kendrick T, et al. An evaluation of a new service model: Improving Access to Psychological 
Therapies demonstration sites 2006-2009, Final Report. Project Report. UK: NIHR Service Delivery and Research Organisation Programme, Project number 08/1610/154. Queen's printer and controller of HMSO England; 2011.

12. Bee P, Lovell $K$, Airnes Z, Pruszynska A. Embedding telephone therapy in statutory mental health services: a qualitative, theory-driven analysis. BMC Psychiatry. 2016;16(1):56. https://doi.org/10.1186/s12888-016-0761-5.

13. May C, Mort M, Mair FS, Williams TL. Factors affecting the adoption of telehealthcare in the United Kingdom: the policy context and the problem of evidence. Health Inform J. 2002;7(3/4):131-4.

14. Rushton K, Fraser C, Gellatly J, Brooks H, Bower P, Armitage CJ, et al. A case of misalignment: the perspectives of local and national decision-makers on the implantation of psychological treatment by telephone in the Improving Access to Psychological Therapies Service. BMC Health Serv Res. 2019;20:36.

15. Vaona A, Pappas Y, Grewal RS, Ajaz M, Majeed A, Car J. Training interventions for improving telephone consultation skills in clinicians. Cochrane Database Syst Rev. 2017;1:CD010034.

16. Canadian Task Force on the Periodic Health Examination. The periodic health examination. Can Med Assoc J. 1979;121:1193-254.

17. Shaneyfelt T. Pyramids are guides not rules: the evolution of the evidence pyramid. BMJ Evid Based Med. 2016;21(4):121-2. https://doi.org/10.1136/ ebmed-2016-110498.

18. Munafò MR, Smith GD. Robust research needs many lines of evidence. Replication is not enough. Nature. 2018;553:399-401.

19. Tonkin-Crine S, Anthierens S, Hood K, Yardley L, Cals JWL, Francis NA, et al. Discrepancies between qualitative and quantitative evaluation of randomised controlled trial results: achieving clarity through mixed methods triangulation. IS. 2015;11:66.

20. Cane J, O'Connor D, Michie S. Validation of the theoretical domains framework for use in behaviour change and implementation research. IS. 2012;7:37.

21. National Health Research England. Patient and Public Participation Policy. 2017. Available from: https://www.england.nhs.uk/wp-content/uploads/201 7/04/ppp-policy.pdf. Accessed 7 May 2020.

22. Gibson A, Britten N, Lynch J. Theoretical directions for an emancipatory concept of patient and public involvement. Health (London). 2012;16(5): 531-47. https://doi.org/10.1177/1363459312438563.

23. Barnes M, Shardlow P. From passive recipient to active citizen: participation in mental health user groups. J Ment Health. 1997;6(3):289-300.

24. Rowe R, Shepherd M. Public participation in the New NHS: No closer to citizen control? Soc Policy Adm. 2002;36(3):275-90. https://doi.org/1 0.1111/1467-9515.00251.

25. Linstone HA, Turoff M. The Delphi method: techniques and applications. Reading: Addison-Wesley; 1975.

26. Delbecq AL, VandeVen AH. A group process model for problem identification and program planning. JABS. 1971;7(4):466-91.

27. Delbecq AL, VandeVen AH, Gustafson DH. Group techniques for program planning: a guide to nominal group and Delphi processes. Glenview: Scott Foresman and Company; 1975.

28. Andreasen PB. Consensus conferences in different countries, aims and perspectives. Int J Technol Assess Health Care. 1988;4(2):305-8. https://doi. org/10.1017/S0266462300004104

29. Jacoby I. The consensus development program of the National Institutes of Health: Current practices and historical perspectives. IJTAHC. 1985:1(2):420-32.

30. Bero LA, Grilli R, Grimshaw J, Harvey E, Oxman A, Thomson MA. Closing the gap between research and practice: an overview of systematic reviews of interventions to promote the implementation of research findings. BMJ. 1998;317(7156):465-8. https://doi.org/10.1136/bmj.317.7156.465.

31. Fitch K, Bernstein SJ, Aguilar MD, Burnand B, LaCalle JM, Lazaro P, et al. The Rand/UCLA appropriateness method user's manual. Santa Monica: RAND Corporation; 2001. Available from: https://www.rand.org/pubs/monograph_ reports/MR1269.html. Accessed 7 May 2020

32. Sekhon M, Cartwright M, Francis JJ. Acceptability of healthcare interventions: an overview of reviews and development of a theoretical framework. BMC Health Serv Res. 2017;17(1):88. https://doi.org/10.1186/s12 913-017-2031-8

33. Hoffmann TC, Glasziou PP, Boutron I, Milne R, Perera R, Moher D, et al. Better reporting of interventions: template for intervention description and replication (TIDieR) checklist and guide. BMJ. 2014;348:91687.
34. Moore GF, Rhiannon EE, Hawkins J, Littlecott H, Melendez-Torres GJ, Bonell $C$, et al. From complex social interventions to interventions in complex social systems: future directions and unresolved questions for intervention development and evaluation. Evaluation. 2018;25(1):23-45. https://doi.org/1 $0.1177 / 1356389018803219$

35. Murray E, Treweek S, Pope C, MacFarlane A, Ballini L, Dowrick C, et al. Normalisation process theory: a framework for developing, evaluating and implementing complex interventions. BMC Med. 2010;8(1):63. https://doi. org/10.1186/1741-7015-8-63.

36. Toomey E, Matvienko-Sikar K, Doherty E, Harrington J, Hayes CB, Heary C, et al. A collaborative approach to developing sustainable behaviour change interventions for childhood obesity prevention: Development of the Choosing Healthy Eating for Infant Health (CHErlsH) intervention and implementation strategy. Br J Health Psychol. 2020;25(2):275-304. https:// doi.org/10.1111/bjhp.12407.

37. Walsh KA, Timmons S, Byrne S, Browne J, Mc Sharry J. Identifying behavior change techniques for inclusion in a complex intervention targeting antipsychotic prescribing to nursing home residents with dementia. Transl Behav Med. 2020:ibaa053. https://doi.org/10.1093/tbm/ibaa053.

38. Riordan F, Racine E, Phillip ET, Bradley C, Lorencatto F, Murphy M, et al. Development of an intervention to facilitate implementation and uptake of diabetic retinopathy screening. IS. 2020;15(1):34. https://doi.org/10.1186/s13 012-020-00982-4.

39. Public Health England. Guidance Process Evaluation. 2018. Available from: https:/www.gov.uk/government/publications/evaluation-in-health-and-wellbeing-overview/process-evaluation. Accessed 7 May 2020.

40. Moore G, Audrey S, Barker M, Bond L, Bonell C, Hardeman W, et al. Process evaluation of complex interventions: Medical Research Council guidance. BMJ. 2015;350(mar19 6):h1258. https://doi.org/10.1136/bmj.h1258.

\section{Publisher's Note}

Springer Nature remains neutral with regard to jurisdictional claims in published maps and institutional affiliations.
Ready to submit your research? Choose BMC and benefit from:

- fast, convenient online submission

- thorough peer review by experienced researchers in your field

- rapid publication on acceptance

- support for research data, including large and complex data types

- gold Open Access which fosters wider collaboration and increased citations

- maximum visibility for your research: over $100 \mathrm{M}$ website views per year

At BMC, research is always in progress.

Learn more biomedcentral.com/submissions 